\title{
Reduced progression of bone erosion in cytomegalovirus seropositive rheumatoid arthritis patients
}

\author{
B. Rauwel', Y. Degboé 1,2,3, D. Nigon 1,3,4, J.-F. Boyer ${ }^{1,2}$, F. Abravanel $^{1,5}$, J. Izopet ${ }^{1,5}$, B. Combe ${ }^{6}$, A. Ruyssen-Witrand ${ }^{1,3,4}$, \\ A. Constantin ${ }^{1,2,3}$, A. Cantagrel ${ }^{1,2,3}$ and J.-L. Davignon ${ }^{1,2^{*}}$
}

\begin{abstract}
Background: Human cytomegalovirus (HCMV) seropositivity has been associated with higher inflammation during rheumatoid arthritis (RA). However, no data are available on the impact of HCMV seropositivity on bone erosion progression during RA.

Methods: We selected 487 individuals of ESPOIR cohort who fulfilled the 2010 ACR/EULAR criteria for RA. HCMV serology for these patients was determined using Architect CMV IgG assay. Baseline and 1-year central X-ray reading using modified Total Sharp Score (mTSS), Erosion Sharp Score, and joint space narrowing Sharp score were used to quantify structural damage progression. We performed univariate and multivariate analyses to investigate the association between HCMV status and bone erosion progression.

Results: We analyzed $273 \mathrm{HCMV}$ seropositive ( $\mathrm{HCMV}+$ ) and $214 \mathrm{HCMV}$ seronegative (HCMV-) RA patients. At inclusion, HCMV+ patients were less frequently ACPA+ $(49.8 \%$ versus $58.9 \%, p<0.0465)$ and had a higher DAS28ESR $(5.55 \pm 1.24$ versus $5.20 \pm 1.14, p<0.0013)$ in comparison with HCMV-. At 1 year, bone erosion progression (delta erosion Sharp score $>1$ point) was lower in HCMV+ patients (16.1\% versus $25.2 \%, p=0.0128$ ) in comparison with HCMV-. HCMV+ status remained independently associated with lower bone erosion progression in multivariate analysis.
\end{abstract}

Conclusions: Our findings suggest that, independently of other confounding factors, HCMV seropositivity is associated with a lower progression of bone erosion during RA.

Keywords: Human cytomegalovirus, Rheumatoid arthritis, Bone erosion, Inflammation, ESPOIR cohort

\section{Background}

Rheumatoid arthritis (RA) is a complex disease resulting of an interaction between genetic factors involved in immunity, environmental events, and epigenetic modifications. Among environmental factors, smoking and infectious agents such as Porphyromonas gingivalis are well described and associated with anti-CCP production [1]. However, other infectious agents such as viruses also could have an impact on RA pathophysiology.

\footnotetext{
* Correspondence: jean-luc.davignon@inserm.fr

${ }^{1}$ Centre de Physiopathologie Toulouse Purpan, U.1043 INSERM, CNRS, Bât A, CHU Purpan, BP 3028, 31024 Toulouse cedex 3, France

${ }^{2}$ Centre de Rhumatologie, $\mathrm{CHU}$ de Toulouse, Toulouse, France

Full list of author information is available at the end of the article
}

In 2012, Pierer et al. analyzed the relationship between human cytomegalovirus (HCMV) infection and RA [2], based on the Steinbrocker radiographic score at a single time point after several years of disease. Their study indicated that a positive serology for HCMV infection is associated with a more severe clinical course of RA.

Recently, our laboratory discovered, in vitro, that HCMV infection is able to inhibit osteoclastogenesis through inhibition of CSF-1R expression [3], which prompted us to consider that HCMV could have an impact on joint destruction evolution during early RA, and more particularly on bone erosion. Using a different approach from a large national prospective cohort, we asked instead whether HCMV could play a role in the evolution of bone erosion in RA. To this end, we chose

(C) The Author(s). 2020 Open Access This article is distributed under the terms of the Creative Commons Attribution 4.0 International License (http://creativecommons.org/licenses/by/4.0/), which permits unrestricted use, distribution, and 
to evaluate the radiographic van der Heijde-modified Sharp score over 1 year of evolution in ESPOIR cohort of early RA patients.

\section{Methods}

\section{ESPOIR cohort}

"ESPOIR" is a multicenter, longitudinal, prospective cohort of 813 French patients with early arthritis. The characteristics of the cohort have been described previously [4]. Briefly, 813 patients with early arthritis recruited in 14 centers in France with arthritis duration < 6 months and no prior treatment with disease-modifying antirheumatic drugs were included in the cohort between 2002 and 2005. Patients underwent clinical, biological, and radiological assessments at baseline and at each subsequent visit. Local institutional review boards approved the study, and written informed consent was obtained from all participants in the study.

Dosages of CRP, IgA, and IgM rheumatoid factor and ACPA were performed. Baseline and 1-year central Xray reading (feet and hands) using modified total Sharp score (mTSS), erosion Sharp score (ESS), and joint space narrowing Sharp score (NSS) were performed by a single experienced rheumatologist (C. Lukas). Intraclass correlation coefficient was calculated from a random sample of 30 radiographs scored twice and was about 0.99 [5]. The smallest detectable change (SDC) was calculated at 1.0 mTSS unit and was derived from distribution-based methods and duplicate reading experience, as explained in the listed reference [5]. Formally, this SDC is thus "the smallest change that can be detected by the instrument beyond measurement error," and patients in whom the change was scored beyond this cutoff value should thus be regarded "real progressors," even though the clinical relevance of such a small value can be discussed at the individual level.

\section{Patients and HCMV serology}

Among the 813 patients included in the ESPOIR cohort, 487 fulfilled the 2010 American College of Rheumatology/European League Against Rheumatism criteria for RA at baseline [6] with a complete dataset of van der Heijde-modified Sharp score radiographic evaluation at baseline and 1 year. HCMV serology for these patients was determined using Architect HCMV IgG assay (Abbott, Chicago, IL, USA).

\section{Statistical analysis}

The Shapiro-Wilk test was performed to assess the normality of continuous data, presented as mean (SD) if normal or median (inter-quartile range [IQR]) else. Qualitative variables are presented as number (percentage).

Comparisons of normally distributed data according to HCMV status were performed with Student test, nonGaussian variables with Mann-Whitney, and dichotomous variables with $\chi^{2}$ test (or Fisher's exact test if the contingency table contains an observed number of occurrences inferior to 5). Odds ratio (OR) was calculated and presented with $95 \%$ confidence interval $(95 \% \mathrm{CI})$ to

Table 1 Characteristics of ESPOIR RA patients at inclusion

\begin{tabular}{|c|c|c|c|c|}
\hline & \multicolumn{4}{|l|}{ ESPOIR cohort } \\
\hline & $\begin{array}{l}\text { All RA patients } \\
(n=487)\end{array}$ & $\begin{array}{l}\text { HCMV seropositive RA patients } \\
(n=273)(56 \%)\end{array}$ & $\begin{array}{l}\text { HCMV seronegative RA patients } \\
(n=214)(44 \%)\end{array}$ & $\begin{array}{l}p(\mathrm{HCMV}+\text { versus } \\
\mathrm{HCMV}-)\end{array}$ \\
\hline \multicolumn{5}{|l|}{ Baseline characteristics (inclusion) } \\
\hline Age, years, median $(I Q R)^{* * *}$ & $50.3(40.0-57.1)$ & $52.9(43.1-58.5)^{* * *}$ & $47.8(37.4-54.3)$ & 0.0001 \\
\hline Gender, female, $n(\%)$ & $378(77.6)$ & $219(80.2)$ & $159(74.3)$ & 0.1197 \\
\hline $\begin{array}{l}\text { Symptom duration, year, median } \\
\text { (IQR) }\end{array}$ & $0.42(0.26-0.64)$ & $0.41(0.25-0.62)$ & $0.42(0.27-0.65)$ & 0.5108 \\
\hline $\mathrm{ACPA}+, n(\%)^{*}$ & $262(53.8)$ & $136(49.8)^{*}$ & $126(58.9)$ & 0.0465 \\
\hline $\mathrm{RF}+, n(\%)$ & $296(60.8)$ & $163(59.7)$ & $133(62.1)$ & 0.5837 \\
\hline $\begin{array}{l}\text { Disease Activity Score } 28 \text { (DAS28- } \\
\text { ESR), mean }(\mathrm{IQR})^{*}\end{array}$ & $5.40( \pm 1.21)$ & $5.55( \pm 1.24)^{*}$ & $5.20( \pm 1.14)$ & 0.0013 \\
\hline $\begin{array}{l}\text { Erythrocyte sedimentation rate (ESR), } \\
\text { median (IQR) }\end{array}$ & $24(12-39)$ & $24(14-46)$ & $22.5(10.5-35.5)$ & 0.0566 \\
\hline C-reactive protein (CRP), median (IQR) & $10(3-24)$ & $9(3-24)$ & $11(3-24)$ & 0.5510 \\
\hline Total Sharp score (TSS), median (IQR) & $4(1-8)$ & $4(1-8)$ & $3(1-8)$ & 0.6745 \\
\hline $\begin{array}{l}\text { Erosion Sharp score (ESS), median } \\
(\mathrm{IQR})\end{array}$ & $1(0-4)$ & $1(0-4)$ & $1(0-4)$ & 0.5420 \\
\hline $\begin{array}{l}\text { Joint space narrowing Sharp score } \\
\text { (NSS), median (IQR) }\end{array}$ & $1(0-4)$ & $1(0-4)$ & $1(0-4)$ & 0.9121 \\
\hline
\end{tabular}

${ }^{*} p<0.05 ;{ }^{* *} p<0.001$ 
Table 2 Treatments and disease characteristics of ESPOIR RA patients 1-year post-inclusion

\begin{tabular}{|c|c|c|c|c|}
\hline & $\begin{array}{l}\text { All RA patients } \\
(n=487)\end{array}$ & $\begin{array}{l}\text { HCMV seropositive RA patients } \\
(n=273)(56 \%)\end{array}$ & $\begin{array}{l}\text { HCMV seronegative RA patients } \\
(n=214)(44 \%)\end{array}$ & $\begin{array}{l}p(\mathrm{HCMV}+\text { versus } \\
\text { HCMV }-)\end{array}$ \\
\hline Patients with DMARD, $n(\%)$ & $417 / 458(91.05)$ & $237 / 262(90.5)$ & 180/196 (91.8) & 0.6090 \\
\hline Use of csDMARD, $n(\%)$ & $376 / 458(82.10)$ & $210 / 262(80.15)$ & 166/196 (84.70) & 0.2100 \\
\hline Use of bDMARD, $n(\%)$ & $41 / 458(8.95)$ & $27 / 262(10.31)$ & $14 / 196(7.14)$ & 0.2410 \\
\hline $\begin{array}{l}\text { Delay between inclusion and first DMARD (months), median } \\
\text { (IQR) }\end{array}$ & $0.38(0.03-1.20)$ & $0.39(0.03-1.22)$ & $0.36(0.07-1.38)$ & 0.5225 \\
\hline Patients with glucocorticoids at baseline, $n$ (\%) & $0(0)$ & $0(0)$ & $0(0)$ & - \\
\hline $\begin{array}{l}\text { Cumulated dose of glucocorticoids between inclusion and } \\
1 \text { year in milligram, median (IQR) }\end{array}$ & $210(0-2120)$ & $646(0-2217)$ & $100(0-1935)$ & 0.1393 \\
\hline Total Sharp score (mTSS), median (IQR) & $4(1-10)$ & $4(1-9)$ & $4(1-10)$ & 0.8913 \\
\hline Delta total Sharp score (0-1 year), mean (SD)* & $1.70(4.49)$ & $1.29(3.38)$ & $2.22(5.57)$ & 0.0238 \\
\hline \multirow[t]{2}{*}{ Delta total Sharp score (0-1 year), median (IQR) } & $0(0-1)$ p95 = 11 & $0(0-1) p 95=9$ & $0(0-2) p 95=13$ & 0.0349 \\
\hline & & \multicolumn{2}{|l|}{$\mathrm{OR}[95 \% \mathrm{Cl}]=0.623[0.464-1.005]$} & 0.0540 \\
\hline \multirow[t]{2}{*}{ Delta Sharp total score $(0-1$ year $)>1, n(\%)^{*}$} & $103(21.2)$ & $47(17.2)^{*}$ & $56(26.3)$ & 0.0151 \\
\hline & & \multicolumn{2}{|l|}{ OR $[95 \% \mathrm{Cl}]=0.583[0.367-0.925]$} & 0.0151 \\
\hline Joint space narrowing Sharp score (NSS), median (IQR) & $1(0-5)$ & $1(0-5)$ & $1(0-4)$ & 0.9121 \\
\hline Delta joint space narrowing Sharp score (0-1 year), mean (SD) & $0.26(1.16)$ & $0.24(1.17)$ & $0.29(1.14)$ & 0.6992 \\
\hline \multirow{2}{*}{$\begin{array}{l}\text { Delta joint space narrowing Sharp score (0-1 year), median } \\
\text { (IQR) }\end{array}$} & $0(0-0) p 95=2$ & $0(0-0) p 95=1$ & $0(0-0) p 95=2$ & 0.4129 \\
\hline & & \multicolumn{2}{|l|}{$\mathrm{OR}[95 \% \mathrm{Cl}]=0.763[0.378-1.541]$} & 0.4129 \\
\hline \multirow[t]{2}{*}{ Joint space narrowing Sharp score (0-1 year), $\Delta>1, n$ (\%) } & $26 / 486(5.3)$ & $13(4.8)$ & $13(6.1)$ & 0.5140 \\
\hline & & \multicolumn{2}{|l|}{ OR $[95 \% \mathrm{Cl}]=0.769[0.321-1.846]$} & 0.5140 \\
\hline Erosion Sharp score (ESS), median (IQR) & $2(0-5)$ & $2(0-5)$ & $2(0-6)$ & 0.9588 \\
\hline Delta erosion Sharp score $(0-1$ year), mean (SD)* & $1.43(3.82)$ & $1.05(2.63)$ & $1.93(4.90)$ & 0.0112 \\
\hline \multirow[t]{2}{*}{ Delta erosion Sharp score $\left(0-1\right.$ year), median $(\mathrm{IQR})^{*}$} & $0(0-1) p 95=9$ & $0(0-1) p 95=8^{*}$ & $0(0-2) p 95=12$ & 0.0172 \\
\hline & & \multicolumn{2}{|l|}{ OR $[95 \% \mathrm{CI}]=0.637[0.432-0.939]$} & 0.0230 \\
\hline \multirow[t]{2}{*}{ Erosion Sharp score (0-1 year), $\Delta>1, n(\%)^{*}$} & $98(20.1)$ & $44(16.1)^{*}$ & $54(25.2)$ & 0.0128 \\
\hline & & \multicolumn{2}{|l|}{ OR $[95 \% \mathrm{Cl}]=0.569[0.355-0.911]$} & 0.0128 \\
\hline
\end{tabular}

${ }^{*} p<0.05$

show the association strength between HCMV status and radiological evolution.

Variable to explain was the presence of more than one new erosion at 1 year in relation to baseline. All the candidate explanatory variables were selected in univariate analysis with $\alpha=20 \%$. A downward logistic regression with $\alpha=5 \%$ was then carried out, to identify covariates independently associated with the variable to explain.

All tests performed for comparison were two-tailed, with $p<0.05$ considered statistically significant.

Data were analyzed with Stata IC 12.1 (StataCorp, College Station, Texas).

\section{Results}

Sera from 487 individuals who fulfilled the 2010 ACR/ EULAR criteria for RA were analyzed for anti-CMV IgG antibodies. A total of 214 patients (44\%) were seronegative and 273 (56\%) seropositive for HCMV. At inclusion, $\mathrm{HCMV}+$ patients were found to be significantly older than $\mathrm{HCMV}$ - patients (median 52.9 years for $\mathrm{HCMV+}, 47.8$ years for HCMV-, $p=0.0001$ ). In addition to being older,
HCMV+ population patients presented a lower proportion of ACPA+ $(49.8 \%$ versus $58.9 \%, p<0.0465)$ and a higher DAS28-ESR $(5.55 \pm 1.24$ versus $5.20 \pm 1.14, p<0.0013)$. No additional significant difference was observed between $\mathrm{HCMV}+$ and HCMV - patients at inclusion (Table 1).

After 1 year, $\mathrm{HCMV}+$ and $\mathrm{HCMV}$ - did not display significant differences in therapy administration. DMARDs and glucocorticoids were similarly administrated in both populations. Although mTSS was not significantly different between HCMV+ and HCMV- patients after 1 year, progression of this score was lower in HCMV+ patients: $17.2 \%$ of HCMV+ patients had a delta total Sharp score $>1$ in comparison with $26.3 \%$ of HCMV - $(p=0.0151)$ (Table 2).

When mTSS was split into joint space narrowing Sharp score (NSS) and erosion Sharp score (ESS), we observed that difference of delta mTSS was only related to ESS change. Indeed, no significant difference was observed on delta NSS between HCMV+ and HCMV- patients $(4.8 \%$ of HCMV+ patients had a delta NSS $>1$ in comparison with $6.1 \%$ of HCMV-, $p=0.5140$ ) (Table 2). However, when looking specifically at ESS, we found that the 


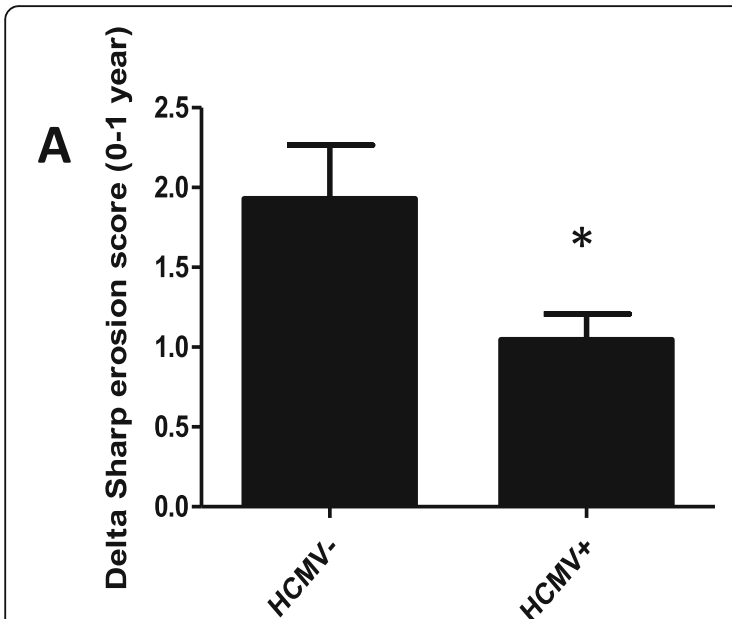

B

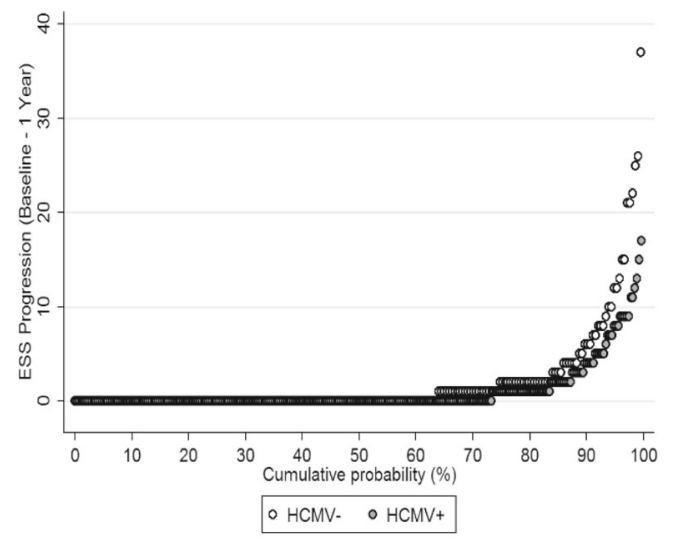

C

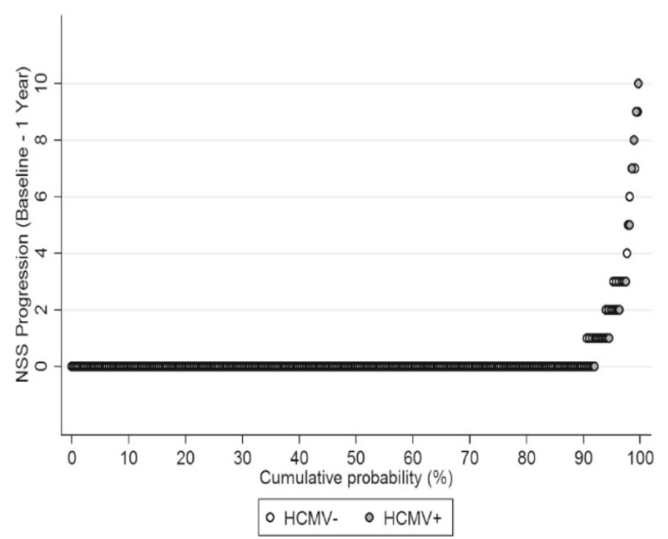

Fig. 1 HCMV seropositivity is associated with a lower bone erosion progression during rheumatoid arthritis, study of ESPOIR cohort. a Delta erosion Sharp score evolution (0-1 year) is represented for 214 HCMV - and 273 HCMV+ RA patients from the ESPOIR cohort. ( $n=$ $487,{ }^{*} p<0.05$, error bars as SD). b, c Cumulative probability plots of the progression of ESS (erosion Sharp score) and NSS (joint space narrowing Sharp score) within 1 year according to HCMV status proportion of patients with delta ESS $>1$ was significantly lower in of $\mathrm{HCMV}+$ patients (16.1\%) as compared to HCMV - patients $(25.2 \%)(p=0.0128)$ (Table 2). Among these patients, $10.3 \%$ of $\mathrm{HCMV}+$ patients $(n=28)$ and $14 \%$ of HCMV - patients $(n=30)$ had a delta ESS $>3(n=$ 58 patients; $p=0.2033$ ). ESS progression was 2 -fold lower in $\mathrm{HCMV}+$ patients in comparison with HCMV- (Fig. 1a), showing an association between HCMV seropositivity and a lower bone erosion progression during RA.

Furthermore, cumulative probability plot showed that ESS was less pronounced in HCMV+ patients (Fig. 1b). NSS was not significantly different (Fig. 1c).

In order to identify covariates independently associated with delta Sharp erosion score $>1$, we performed a multivariate analysis (including parameters associated in univariate analysis with $\alpha=20 \%$ : age, gender, ACPA, RF, HCMV, DAS28-ESR, CRP, duration of disease course before inclusion, smoking consumption, glucocorticoids treatment, erosion Sharp score at baseline, bDMARD, and CSDMARD). ACPA+ status was more frequent in HCMV - patients. We forced the multivariate model with the use of a bDMARD or a csDMARD at year 1 . The results demonstrated that while ACPA were, as expected, associated with progression of erosion, HCMV seropositivity was nevertheless still associated with lower progression (Table 3, OR $=0.5255, \mathrm{CI}=0.2998$ to $0.9213, p=0.025$ ).

\section{Discussion}

Although HCMV+ status was previously described to be associated with more severe joint disease [2], we show here, from a large cohort of early RA patients, that HCMV seropositivity is associated with a lower progression of bone erosion in the first year of the disease despite higher DAS.

This discrepancy could result from a longer history of RA disease in patients evaluated in Pierer et al. compared with RA patients in the first year of the disease used in our current work. Analysis of joint destruction was also different as Steinbrocker score analyzes qualitative bone destruction, contrary to the Sharp-van der Heijde score which gives a quantitative measurement of joint destruction and can discriminate joint space narrowing and bone erosion. Finally, joint damage was measured at a given time point in Pierer et al., whereas the ESPOIR cohort was designed for analysis of progression.

Overall, apparent contradiction between higher DAS and lower bone erosion in $\mathrm{HCMV}+$ patients can be pointed out in our current study. This could result from dissociation of HCMV-induced inflammation [7] from its specific effect on bone erosion observed here over 1 year. In this respect, HCMV may indeed aggravate RA disease over time. The Steinbrocker score used in the paper by Pierer et al. that is not specific for bone erosion may reflect the inflammatory status as a whole at a given 
Table 3 Multivariate analysis of the association between HCMV seropositivity and ESS progression during RA, study of ESPOIR cohort

\begin{tabular}{|c|c|c|c|c|c|c|}
\hline Erosion Sharp score (baseline-1 year) score $\Delta>1$ & Odds ratio & Standard error & $z$ & $P>|z|$ & {$[95 \%$ co } & val] \\
\hline Erosion Sharp score at baseline & 5.3180 & 1.9356 & 4.59 & 0.000 & 2.6057 & 10.854 \\
\hline ACPA+ & 5.1915 & 1.7635 & 4.85 & 0.000 & 2.6677 & 10.103 \\
\hline HCMV & 0.5255 & 0.1505 & -2.25 & 0.025 & 0.2998 & 0.9213 \\
\hline Cumulated dose of glucocorticoids & 0.9997 & 0.0001 & -2.29 & 0.022 & 0.9995 & 1 \\
\hline Use of csDMARDs & 1.7987 & 1.0696 & 0.99 & 0.324 & 0.5608 & 5.7694 \\
\hline Use of bDMARDs & 1.3298 & 0.9829 & 0.39 & 0.700 & 0.3123 & 5.6619 \\
\hline
\end{tabular}

time point. Conversely, the 1-year Sharp erosion score as in our current study of the ESPOIR cohort may best evaluate the evolution of specific bone degradation at the early phase of the disease. Although the average change in radiographic damage that was observed in the ESPOIR cohort was limited, which might be due to an overall milder disease, early therapeutic interventions and close follow-up, or even more probably a combination of such effects, it must be accepted that the changes that were observed and scored, although of limited amplitude and in occurring a restricted population only, are definitely real. Our observations were based on a delta ESS $>1$. Nevertheless, we performed the analysis with a cutoff of 3 and observed a non-significant smaller proportion of HCMV+ RA patients (10.3\% versus $14 \%$, $p=0.2033)$. This result may be related to a lack of statistical power due to the small number of patients $(n=58)$. Our study provides some insight in the population of patients with low ranges of the progression score. Our findings need to be confirmed in a population with higher ranges of progression score.

Since HCMV seropositivity relies on the presence of IgG antibodies in sera of RA patients, it is impossible to know when the primo-infection occurred in patients. HCMV, which establishes a lifelong persistence in the human host, is in a latent state in seropositive individuals, including RA patients. How latent HCMV infection, during which no viral protein is expressed, leads to decreased bone erosion is unknown. Since HCMV can reactivate from latency during monocytes differentiation into dendritic cells or macrophages, we can hypothesize that local reactivation in the synovium can lead to inhibition of OCs differentiation. It has been repeatedly shown that HCMV can reactivate in various organs and can be released in fluids [8]. Whether synovial membranes of HCMV+ RA patients are a site of viral reactivation is to be determined through the measurement of viral copy numbers ex vivo. Indeed, HCMV DNA was found infrequently in the synovial fluids of RA patients $[9,10]$. Since inflammation has been associated with reactivation [11], it is possible that a proportion of RA patients reactivate their latent HCMV during disease flare. However, other mechanisms can be envisaged as well. Alternatively, cellular protein(s), induced during the primo-infection that would remain expressed throughout the course of the disease, may result in less severe bone erosion. Those hypotheses will have to be explored to explain how RA patients are protected from bone erosion. In this respect, diminished expression of CSF1-R in cells infected by HCMV has been reported by Frascaroli et al. [12]. This may explain why HCMV infection inhibits the differentiation of monocytes into OCs [3]. We have further identified an mRNA-binding protein that is induced by HCMV infection and directly inhibits the expression of CSF1-R. Its expression in RA patients and its contribution to protection from erosion is not known. Additional file 1: Figure S1 gives a tentative insight into how we envisage the impact of HCMV on inflammation and bone erosion. How this protein is relevant to inhibition of bone erosion specifically in RA patients is to be further investigated.

\section{Conclusions}

Our report suggests that during RA, HCMV is associated with a lower bone erosion progression while contributing to inflammation.

\section{Supplementary information}

Supplementary information accompanies this paper at https://doi.org/10. 1186/s13075-020-2098-1.

Additional file 1: Figure S1. HCMV infection inhibits the expression of CSF-1R, thus providing a putative mechanism for the reduced progression of erosion in seropositive patients. (PPTX 196 kb)

\begin{abstract}
Abbreviations
HCMV: Human cytomegalovirus; ACR: American College of Rheumatology; EULAR: European League Against Rheumatism; RA: Rheumatoid arthritis; mTSS: Modified total Sharp score; NSS: Joint space narrowing Sharp score; ESS: Erosion sharp score; ACPA: Anti-citrullinated protein antibody; CRP: Creactive protein; IQR: Inter-quartile range; OR: Odd ratio; IC: Confidence interval; DMARD: Disease-modifying anti-rheumatic drugs; ESR: Erythrocyte sedimentation rate; RF: Rheumatoid factor
\end{abstract}

\section{Acknowledgements}

We thank Merck Sharp and Dohme, Inserm, The French Society of Rheumatology, Pfizer, AbbVie, Roche-Chugai, and Lilly who supported the ESPOIR cohort study. We also wish to thank Nathalie Rincheval (CHU Montpellier and EA 2415) who did expert monitoring and data management, all the investigators who recruited and followed up the patients ( $F$. Berenbaum, Paris-Saint Antoine, MC. Boissier, Paris-Bobigny, A. Cantagrel, Toulouse, B. Combe, Montpellier, M. Dougados, Paris-Cochin, P Fardelone et P Boumier Amiens, B. Fautrel, Paris-La Pitié, RM. Flipo, Lille, Ph. Goupille, Tours, F. Liote, 
Paris- Lariboisière, O Vittecoq, Rouen, X Mariette, Paris Bicetre, O Meyer et Ph Dieude, Paris Bichat, A.Saraux, Brest, Th Schaeverbeke, Bordeaux, J. Sibilia, Strasbourg) and Cedric Lukas for reading X-rays.

\section{Author's contributions}

All authors were involved in drafting the article or revising it critically for important intellectual content, and all authors approved the final version to be published. BR and JLD had full access to all of the data in the study and take responsibility for the integrity of the data and the accuracy of the data analysis. BR, BC, ARW, AC, AC, and JLD contributed to the study conception and design. FA and $\mathrm{Jl}$ contributed to the HCMV serology. BR, YD, JFB, DN, Jl, $B C, A R W, A C, A C$, and JLD contributed to the analysis and interpretation of data.

\section{Funding}

This work was funded by Institutional grants from Inserm-CNRS.

\section{Availability of data and materials}

All data and material concerning ESPOIR cohort were available on the website http://www.lacohorteespoir.fr/

\section{Ethics approval and consent to participate}

The ESPOIR study was conducted with the approval of the Institutional Review Board of Montpellier University Hospital, the coordinating center, and was conducted in accordance with the Declaration of Helsinki and the guidance for good clinical practice (French version), 30 November 2006. All patients gave their signed informed consent to participate in the cohort.

\section{Consent for publication}

No individual person's data are present in this manuscript. All data are completely anonymized. All patients gave their signed informed consent to participate in the cohort.

\section{Competing interests}

The authors declare that they have no competing interests.

\section{Author details}

${ }^{1}$ Centre de Physiopathologie Toulouse Purpan, U.1043 INSERM, CNRS, Bât A, CHU Purpan, BP 3028, 31024 Toulouse cedex 3, France. ${ }^{2}$ Centre de Rhumatologie, CHU de Toulouse, Toulouse, France. ${ }^{3}$ Faculté de Médecine, Université Paul Sabatier Toulouse III, Toulouse, France. ${ }^{4}$ UMR1027, INSERM Université Paul Sabatier Toulouse III, Toulouse, France. ${ }^{5} \mathrm{CHU}$ de Toulouse, Hôpital Purpan, Laboratoire de Virologie, Toulouse, France. ${ }^{6}$ Département de Rhumatologie, CHU Montpellier, Université de Montpellier, Montpellier, France.

Received: 5 July 2019 Accepted: 9 January 2020

Published online: 20 January 2020

\section{References}

1. Smolen JS, Aletaha D, McInnes IB. Rheumatoid arthritis. Lancet. 2016;388: 2023-38.

2. Pierer M, Rothe K, Quandt D, Schulz A, Rossol M, Scholz R, et al. Association of anticytomegalovirus seropositivity with more severe joint destruction and more frequent joint surgery in rheumatoid arthritis. Arthritis Rheum. 2012; 64:1740-9.

3. Rauwel B, Baron M, Ruyssen-Witrand A, Nigon D, Degboé Y, Izopet J, et al. Evidence for inhibition of osteoclastogenesis by cytomegalovirus infection: implication in RA bone erosion and identification of a cellular protein as a therapeutic target. Abstr Arthritis Rheumatol. 2017;69(suppl 10):2017.

4. Combe B, Benessiano J, Berenbaum F, Cantagrel A, Daures JP, Dougados M, et al. The ESPOIR cohort: a ten-year follow-up of early arthritis in France: methodology and baseline characteristics of the 813 included patients. Joint Bone Spine. 2007;74:440-5.

5. Lukas C, Combe B, Ravaud P, Sibilia J, Landew R, van der Heijde D. Favorable effect of very early disease-modifying antirheumatic drug treatment on radiographic progression in early inflammatory arthritis: data from the Etude et Suivi des polyarthrites indifferenciees recentes (study and followup of early undifferentiated polyarthritis). Arthritis Rheum. 2011;63: 1804-11.
6. Aletaha D, Neogi T, Silman AJ, Funovits J, Felson DT, Bingham CO, et al. 2010 Rheumatoid arthritis classification criteria: an American College of Rheumatology/European League Against Rheumatism collaborative initiative. Arthritis Rheum. 2010;62:2569-81.

7. Mocarski ES. Virus self-improvement through inflammation: no pain, no gain. Proc Natl Acad Sci U A. 2002;99:3362-4.

8. Griffiths P, Baraniak I, Reeves M. The pathogenesis of human cytomegalovirus. J Pathol. 2015;235:288-97.

9. Murayama T, Tsuchiya N, Jisaki F, Ozaki M, Sakamuro D, Hirai K, et al. Elevated cytokine levels in synovial fluid of rheumatoid arthritis correlates with the presence of cytomegalovirus genome. Autoimmunity. 1994;17: 333-7.

10. Stahl HD, Hubner B, Seidl B, Liebert UG, van der Heijden IM, Wilbrink B, et al. Detection of multiple viral DNA species in synovial tissue and fluid of patients with early arthritis. Ann Rheum Dis. 2000;59:342-6.

11. Dupont $L$, Reeves MB. Cytomegalovirus latency and reactivation: recent insights into an age old problem. Rev Med Virol. 2016;26:75-89.

12. Frascaroli G, Varani S, Blankenhorn N, Pretsch R, Bacher M, Leng L, et al. Human cytomegalovirus paralyzes macrophage motility through downregulation of chemokine receptors, reorganization of the cytoskeleton, and release of macrophage migration inhibitory factor. J Immunol. 2009;182: 477-88.

\section{Publisher's Note}

Springer Nature remains neutral with regard to jurisdictional claims in published maps and institutional affiliations.
Ready to submit your research? Choose BMC and benefit from:

- fast, convenient online submission

- thorough peer review by experienced researchers in your field

- rapid publication on acceptance

- support for research data, including large and complex data types

- gold Open Access which fosters wider collaboration and increased citations

- maximum visibility for your research: over $100 \mathrm{M}$ website views per year

At $\mathrm{BMC}$, research is always in progress.

Learn more biomedcentral.com/submissions 